\title{
Kontribusi Stresor dan Motivasi Kerja Terhadap Kinerja Tenaga Kependidikan Berdasarkan Uraian Tugasnya di Institusi Pendidikan Kesehatan Karya Husada Kediri (Sebuah Analisis Jalur)
}

\author{
Wahyu Nuraisya, Firman F. Wirakusumah, Tina Dewi Judistiani \\ Fakultas Kedokteran Universitas Padjajaran, Bandung
}

\begin{abstract}
Background: Quality of management education is an important aspect for the continuity of education and the acquisition of quality outcomes. Human resource management requires good performance of educational personnel in providing services to students and the lecturers themselves supporting the implementation of tasks. For the lecturers, the demand of task implementation is sort of a stressor. A good motivation well-achieved the performance of educational personnel.

Aim: This study aims to determine the corelation of stressors and motivation of the lecturers' performance based on job descriptions in the work of health education institution Husada Kediri.

Method:This study is an analytical research correlated with cross-cutting approach. The population is all educational personnel in health education institution Husada Kediri. Study sample was 50 educational staff with a total population of the technique. Collecting date using questionnaire.

Discussion:The results of correlation analysis using Pearson test found that work stressors negatively correlated $(r=-0.315)$ with the performance, and there is a positive correlation $(r=0.408)$ between work motivation and performance. The results of analysis using path analysis showed a influence between stressors and simultaneously with the performance of work motivation with square values of $r=0.359$ and the influence of other variables that are not observed at 0.641 .

Conclusion:Low work stressors and highly motivation could raise the performance of the educational personnel at health education institute Karya Husada Kediri so in that way there is much more thing to do how to deal with work stressors and motivational improvement to gain better performance.
\end{abstract}

Keywords: performance, work motivation, job stressors, educational personnel, job descriptions

\begin{abstract}
Abstrak
Latar Belakang: Kualitas manajemen pendidikan merupakan aspek penting dalam kelangsungan pendidikan dan perolehan iuaran yang berkualitas. Manajemen sumber daya manusia menuntut kinerja yang baik dari tenaga kependidikan dalam memberikan pelayanan kepada mahasiswa dan mendukung pelaksanaan tugas tenaga pendidik.Bagi tenaga kependidikan, tuntutan pelaksanaan tugas merupakan stresor.Motivasi Kerja yang baik mendorong peningkatan kinerja tenaga kependidikan.

Tujuan: Tujuan penelitian ini adalah untuk menganalisis pengaruh antara stresor dan motivasi kerja terhadap kinerja tenaga kependidikan berdasarkan uraian tugasnya.

Metode: Penelitian ini merupakan penelitian analitik korelatif dengan pendekatan potong silang. Populasi adalah seluruh tenaga kependidikan di institusi pendidikan kesehatan Karya Husada Kediri.Sampel penelitian adalah 50 tenaga kependidikan dengan teknik total populasi.Pengumpulan data dengan menggunakan kuesioner.Data yang terkumpul diuji secara analisis jalur.
\end{abstract}

Korespondensi: Korespondensi: w.nuraisya@gmail.com

Departemen Pendidikan Nasional, Universitas Padjajaran, Fakultas Kedokteran,Program Pascasarjana

Jl.Eijkman no 38, Bandung 40132 Email: pascasarjana@fk.unpad.ac.id 
Hasil dan Pembahasan: Stresor kerja berkorelasi negatif $(r=-0,315)$ dengan kinerja, dan terdapat korelasi positif $(\mathrm{r}=0,408)$ antara motivasi kerja dengan kinerja. Hasil analisis yang menggunakan uji analisis jalur menunjukkan adanya pengaruhbaik pengaruh langsung maupun tidak langsung terhadap kinerja tenaga kependidikan berdasarkan uraian tugasnya di institusi pendidikan kesehatan Karya Husada Kediri sebesar $\left(\mathrm{R}^{2}=0,359\right)$. Dan pengaruh variabel lain yang tidak diteliti sebesar 0,641.

Kesimpulan: Stresor kerja yang rendah dan motivasi yang tinggi meningkatkan kinerja tenaga kependidikan di institusi pendidikan kesehatan Karya Husada Kediri, sehingga masih perlu pengelolaan stresor kerja dan perbaikan motivasi untuk meningkatkan kinerja.

Kata Kunci: kinerja, motivasi kerja, stresor kerja, tenaga kependidikan, uraian tugas

\section{PENDAHULUAN}

Sistem pendidikan nasional mempunyai peran utama dalam mengelola pengembangan dan pembinaan sumber daya manusia (SDM) sebagai kekuatan sentral dalam proses pembangunan. Salah satu bidang penting dalam administrasi/ manajemen pendidikan adalah berkaitan dengan personil, baik itu peserta didik, tenaga pendidik maupun tenaga kependidikan. ${ }^{3}$ Tenaga pendidik dengan tenaga kependidikan merupakan sumber daya manusia yang saling berkaitan dalam proses meningkatkan kualitas pendidikan. Pencapaian keberhasilan proses pendidikan diperlukan kinerja yang baik dari tenaga kependidikan dengan melaksanakan uraian tugasnya.

Penilaian kinerja idealnya dilakukan secara tertib, objektif dan berkelanjutan. Setiap institusi pendidikan kesehatan harus memiliki perencanaan kinerja, menentukan bagaimana kinerja harus diukur, mengenali dan merencanakan cara mengatasi kendala, serta mencapai pemahaman bersama tentang pekerjaannya. Kinerja akan menjadi baik apabila tenaga kependidikan dalam melaksanakan tugasnya mempunyai kondisi yang stabil baik fisik, psikis maupun perilaku. Stresor kerja merupakan kondisi psikis yang dapat mempengaruhi emosi, dan kemampuan tenaga kependidikan dalam proses berpikir dan bekerja. Perubahan kondisi tersebut akan menentukan motivasi dari tenaga kependidikan dalam pencapaian prestasi kerja yang baik.

\section{METODE}

Penelitian ini adalah analitik korelatif dengan metode potong lintang (cross sectional).Populasi dalam penelitian ini adalah semua tenaga kependidikan di institusi pendidikan kesehatan Karya Husada Kediri dengan teknik sampling total populasi.Pengumpulan data dilaksanakan pada tanggal 10 Februari sampai dengan 20 Maret tahun 2012.Jenis data yang dipergunakan adalah data primer dengan instrumen pengumpulan data menggunakan kuesioner.Data yang terkumpul dilakukan uji analisis jalur.

\section{HASIL DAN PEMBAHASAN}

\section{Distribusi Frekuensi Umur, Jenis Kelamin, Tingkat Pendidikan dan Lama Kerja}

Distribusi frekuensi umur, jenis kelamin, tingkat pendidikan dan lama kerja dapat dilihat pada Tabel 1 .

Jumlah responden dari 50 orang tenaga kependidikan yang memenuhi kriteria inklusi dan eksklusi adalah sebanyak 48 orang, 2 orang yang dikeluarkan pada waktu penelitian karena 1 orang sedang masa cuti melahirkan dan 1 orang lagi mengundurkan diri sebagai tenaga kependidikan di institusi pendidikan Karya Husada Kediri. Sehingga berdasarkan hasil analisis karakteristik responden tampak seperti pada Tabel 1 dapat dijelaskan bahwa dari 48 responden yang diteliti untuk karakteristik berdasarkan usia, responden tertinggi adalah kelompok usia $>40$ tahun yaitu 50\% (24 orang). Jenis kelamin tenaga kependidikan sebagian besar adalah laki-laki yaitu 60,4\% (29 orang), dan berdasarkan tingkat pendidikan paling banyak responden berpendidikan SMA-Diploma yaitu 45,8\% (22 orang), sedangkan lama kerja tenaga kependidikan paling banyak <20 tahun sebanyak 72,9\% (35 orang). 
Tabel 1. Tabel karakteristik tenaga kependidikan di institusi

PendidikanKesehatan Karya Husada Kediri $(n=48)$

\begin{tabular}{lcc} 
Karakteristik Responden & Jumlah & Persentase (\%) \\
Usia (tahun) & & \\
$20-30$ th & 6 & 12,5 \\
$31-40$ th & 18 & 37,5 \\
$>40$ th & 24 & 50 \\
\hline Jenis Kelamin & \\
Laki-laki & 29 & 60,4 \\
Perempuan & 19 & 39,6 \\
\hline Tingkat pendidikan & \\
SD - SMP & & 22,9 \\
SMA - Diploma & 11 & 45,8 \\
Sarjana & 22 & 31,3 \\
\hline Lama bekerja & 15 & \\
< 20 tahun & & 72,9 \\
$\geqslant 20$ tahun & 35 & 27,1 \\
\hline
\end{tabular}

Proporsi Stresor Kerja, Motivasi Kerja dan Kinerja Tenaga Kependidikan Berdasarkan Uraian Tugasnya di Institusi Pendidikan Kesehatan Karya Husada Kediri

Proporsi stresor kerja, motivasi kerja dan kinerja melalui penilaian uraian tugas tenaga kependidikan dapat dilihat pada Tabel 2 di bawah ini:

Tabel 2. Tabel proporsi stresor kerja, motivasi kerja dan kinerja tenaga kependidikan berdasarkan uraian tugasnya di institusi pendidikan kesehatan Karya Husada Kediri

\begin{tabular}{|c|c|c|c|c|c|c|c|c|}
\hline \multirow{3}{*}{ Variabel } & \multirow{3}{*}{ Kategori } & \multicolumn{6}{|c|}{ Kinerja } & \multirow{3}{*}{ Total } \\
\hline & & \multicolumn{2}{|c|}{ Rendah } & \multicolumn{2}{|c|}{ Sedang } & \multicolumn{2}{|c|}{ Tinggi } & \\
\hline & & & & $\mathrm{n}$ & & $\mathrm{n}$ & & \\
\hline \multirow{3}{*}{ Stresor kerja } & Rendah & 4 & 20 & 10 & 50 & 6 & 30 & 20 \\
\hline & Sedang & 8 & 53,3 & 7 & 46,7 & 0 & 0 & 15 \\
\hline & Tinggi & 4 & 30,8 & 9 & 69,2 & 0 & 0 & 13 \\
\hline \multicolumn{2}{|c|}{ Total } & 16 & 33,3 & 26 & 54,2 & 6 & 12,5 & 48 \\
\hline \multirow{3}{*}{$\begin{array}{c}\text { Motivasi } \\
\text { kerja }\end{array}$} & Rendah & 8 & 42,1 & 11 & 57,9 & 0 & 0 & 19 \\
\hline & Sedang & 5 & 29,4 & 12 & 70,6 & 0 & 0 & 17 \\
\hline & Tinggi & 3 & 25 & 3 & 25 & 6 & 50 & 12 \\
\hline \multicolumn{2}{|c|}{ Total } & 16 & 33,3 & 26 & 54,2 & 6 & 12,5 & 48 \\
\hline
\end{tabular}


Hasil analisis untuk stresor kerja tenaga kependidikan sebagian besar dalam kondisi rendah yaitu 41,2\% (20 orang), sedangkan untuk motivasi kerja tenaga kependidikan sebagian besar mempunyai motivasi rendah yaitu 39,6\% (19 orang). Hasil penilaian kinerja berdasarkan uraian tugasnya sebagian besar memiliki kinerja sedang 54,2\% (26 orang).
Tabulasi Silang Karakteristik Responden dengan Kinerja Tenaga Kependidikan Berdasarkan Uraian Tugasnya di Institusi Pendidikan Kesehatan Karya Husada Kediri

Tabulasi silang antara umur, jenis kelamin, tingkat pendidikan, dan masa kerja dengan kinerja tenaga kependidikan adalah sebagai berikut:

Tabel 3.Tabulasi silang karakteristik responden dengan kinerjatenaga kependidikan berdasarkan uraian tugasnya di institusipendidikan kesehatanKarya Husada Kediri

\begin{tabular}{|c|c|c|c|c|c|c|c|}
\hline \multirow{3}{*}{ Variabel } & \multicolumn{6}{|c|}{ Kinerja } & \multirow{3}{*}{ Nilai p } \\
\hline & \multicolumn{2}{|c|}{ Rendah } & \multicolumn{2}{|c|}{ Sedang } & \multicolumn{2}{|c|}{ Tinggi } & \\
\hline & $\bar{n}$ & $\%$ & $\mathrm{n}$ & $\%$ & $\mathrm{n}$ & $\%$ & \\
\hline Usia & & & & & & & 0,052 \\
\hline 20-30 tahun & 0 & 0 & 6 & 100 & 0 & 0 & \\
\hline $31-40$ tahun & 4 & 22,2 & 11 & 61,1 & 3 & 16,7 & \\
\hline$>40$ tahun & 12 & 50 & 9 & 37,5 & 3 & 12,5 & \\
\hline Jenis kelamin & & & & & & & 0,002 \\
\hline Laki-laki & 15 & 51,7 & 10 & 34,5 & 4 & 13,8 & \\
\hline Percmpuan & 1 & 5,3 & 16 & 84,2 & 2 & 10,5 & \\
\hline Tingkat & & & & & & & 0,092 \\
\hline pendidikan & 7 & 63,6 & 2 & 18,2 & 2 & 18,2 & \\
\hline$S I)-S M P$ & 5 & 22,7 & 15 & 68,2 & 2 & 9,1 & \\
\hline SMA-Diploma & 4 & 20,1 & 9 & 60 & 2 & 13,3 & \\
\hline Sarjana & & & & & & & \\
\hline Lama kcrja & & & & & & & 0,790 \\
\hline$<20$ tahun & 11 & 31,4 & 19 & 54,3 & 5 & 14,3 & \\
\hline$\geqslant 20$ tahun & 5 & 38,5 & 7 & 53,8 & 1 & 7,7 & \\
\hline
\end{tabular}

Keterangan: diuji dengan menggunakan uji Chi-Square

Berdasarkan Tabel diatas, dapat disimpulkan diantara karakteristik umur, jenis kelamin, tingkat pendidikan dan lama kerja hanya pada jenis kelamin yang memiliki hubungan bermakna $(\mathrm{p}<0,05)$ dengan kinerja.

Korelasi antara Stresor Kerja dan Motivasi Kerja dengan Kinerja Tenaga Kependidikan Berdasarkan Uraian Tugasnya di Institusi Pendidikan Kesehatan Karya Husada Kediri

Korelasi antara stresor kerja dan motivasi kerja dengan kinerja tenaga kependidikan berdasarkan uraian tugasnya dapat dilihat pada tabel 4 .
Tabel 4. Korelasi antara Stresor Kerja dan Motivasi Kerja dengan KinerjaTenaga Kependidikan Berdasarkan Uraian Tugasnya di institusi Pendidikan Kesehatan Karya Husada Kediri

\begin{tabular}{ccc}
$\begin{array}{c}\text { Korelasi kinerja } \\
\text { dengan : }\end{array}$ & $\begin{array}{c}\text { Koefisien } \\
\text { korelasi }(\mathbf{r})\end{array}$ & $\begin{array}{c}\text { Nilai } \\
\mathbf{p}\end{array}$ \\
\hline Stresor kerja & $-0,311$ & 0,031 \\
\hline Motivasi kerja & 0,408 & 0,004 \\
\hline
\end{tabular}

$\overline{\text { Nilai } r \text { dihitung berdasarkan uji korelasi Pearson }}$ 
Berdasarkan Tabel 4 tampak bahwa terdapat korelasi yang bermakna $(p<0,05)$ antara stresor kerja dengan kinerja tenaga kependidikan berdasarkan uraian tugasnya. Begitu juga dengan motivasi kerja mempunyai korelasi yang bermakna $(\mathrm{p}<0,05)$ antara motivasi kerja dengan kinerja tenaga kependidikan berdasarkan uraian tugasnya.

Pengaruh antara Stresor Kerja dan Motivasi Kerja terhadap Kinerja Tenaga Kependidikan Berdasarkan Uraian Tugasnya di Institusi Pendidikan Kesehatan Karya Husada Kediri

Pengujian yang akan dilakukan adalah untuk mengetahui besar pengaruh langsung dan tidak langsung variabel X terhadap variabel Y. Dari hasil statistik diperoleh bahwa stresor kerja dan motivasi kerja secara bersamasama mempengaruhi kinerja tenaga kependidikan dengan koefisien determinasi 0,359 dan secara parsial stresor kerja dan motivasi kerja berpengaruh terhadap kinerja dengan koefisien jalur masing-masing 0,254 dan 0,495 serta koefisien korelasi 0,165. Pengaruh variabel lain yang tidak dimasukkan kedalam model ( $\rho y \varepsilon$ ) adalah

$$
\operatorname{Pys}=\sqrt{1-R^{2} y(x 1 \times 2)}=\sqrt{1-0,395}=0,777
$$

Berdasarkan hal diatas, selanjutnya dapat dibuat diagram jalur pengaruh sebagai berikut:

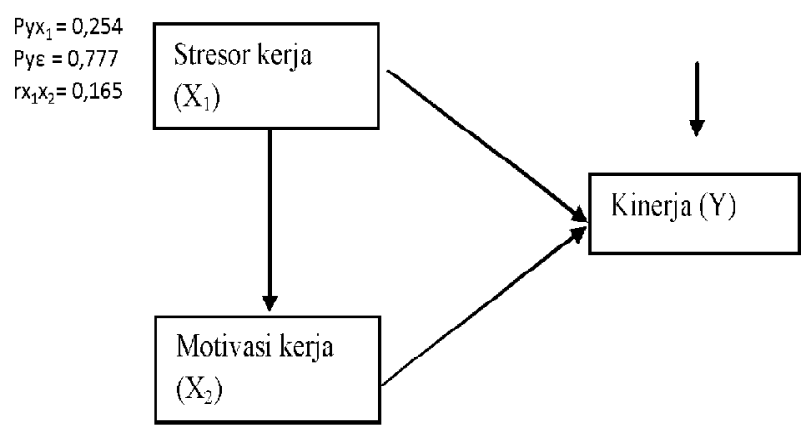

Dengan memperhatikan gambar diatas, maka diperoleh persamaan jalur sebagai berikut: $Y=0,254 \mathrm{X}_{1}+0,495 \mathrm{X}_{2}$ + å

Pengaruh langsung dan tidak langsung stresor kerja $\left(\mathrm{X}_{1}\right)$ terhadap kinerja $(\mathrm{Y})$ tenaga kependidikan berdasarkan uraian tugasnya di institusi pendidikan kesehatan Karya Husada Kediri

Berikut akan ditampilkan pengaruh langsung dan tidak langsung stresor kerja $\left(\mathrm{X}_{1}\right)$ terhadap kinerja $(\mathrm{Y})$ tenaga kependidikan berdasarkan uraian tugasnya di institusi pendidikan kesehatan Karya Husada Kediri

Tabel 5. Pengaruh langsung dan tidak langsung stresor kerja $\left(\mathrm{X}_{1}\right)$ terhadap kinerja (Y) tenaga kependidikan berdasarkan uraian tugasnya di institusi pendidikan kesehatan Karya Husada Kediri

\begin{tabular}{lll}
\hline $\mathrm{X}_{1}$ langsung & $0,254 \times 0,254 \times 100 \%$ & $=6,45 \%$ \\
\hline $\mathrm{X}_{1}{\text { melalui } \mathrm{X}_{2}} \begin{array}{l}0,254 \times 0, \quad 165 \times 0,495 \times \\
100 \%\end{array}$ & $=2,07 \%$ \\
\hline Total pengaruh $\mathrm{X}_{1} \quad$ terhadap $\mathrm{Y}$ & $=8,52 \%$ \\
\hline
\end{tabular}

Dari Tabel diatas, dapat diketahui bahwa total pengaruh yang diberikan oleh stresor kerja terhadap kinerja adalah $8,52 \%$.
Pengaruh langsung dan tidak langsung motivasi kerja $\left(\mathrm{X}_{2}\right)$ terhadap kinerja $(\mathrm{Y})$ tenaga kependidikan berdasarkan uraian tugasnya di institusi pendidikan kesehatan Karya Husada Kediri

Berikut akan ditampilkanpengaruh langsung dan tidak langsung motivasi kerja $\left(\mathrm{X}_{2}\right)$ terhadap kinerja $(\mathrm{Y})$ tenaga kependidikan berdasarkan uraian tugasnya di institusi pendidikan kesehatan Karya Husada Kediri 
Tabel 6. Pengaruh langsung dan tidak langsung motivasi kerja $\left(\mathrm{X}_{2}\right)$ terhadap

kinerja (Y) tenaga kependidikan berdasarkan uraian tugasnya di institusi pendidikan kesehatan Karya Husada Kediri

\begin{tabular}{lll}
\hline $\mathrm{X}_{2}$ langsung & $0,495 \times 0,495 \times 100 \%$ & $=24,50 \%$ \\
\hline $\mathrm{X}_{2}$ melalui $\mathrm{X}_{1}$ & $0,495 \times 0,165 \times 0,254 \times 100 \%$ & $=2,07 \%$ \\
\hline Total pengaruh $\mathrm{X}_{2}$ terhadap $\mathrm{Y}$ & $=26,54 \%$ \\
\hline
\end{tabular}

Dari tabel diatas, dapat diketahui bahwa total pengaruh yang diberikan oleh motivasi kerja terhadap kinerja adalah 26,54\%.Dengan demikian dapat dikemukakan bahwa stresor kerja dan motivasi kerja secara bersama memiliki pengaruh langsung terhadap kinerja sebesar $30,95 \%$, sedangkan pengaruh tidak langsung sebesar 4,14\%. Sehingga pengaruh stresor kerja dan motivasi kerja secara bersama baik pengaruh langsung maupun tidak langsung terhadap kinerja tenaga kependidikan berdasarkan uraian tugasnya di institusi pendidikan kesehatan Karya Husada Kediri sebesar 35,09\%. Dan pengaruh variabel lain yang tidak diteliti sebesar $64,91 \%$.

\section{PEMBAHASAN}

Korelasi Stresor Kerja dengan Kinerja Tenaga Kependidikan Berdasarkan Uraian Tugasnya di Institusi Pendidikan Kesehatan Karya Husada Kediri

Dari hasil uji statistik tampak bahwa terdapat korelasi yang bermakna $(\mathrm{p}<0,05)$ antara stresor kerja dengan kinerja tenaga kependidikan berdasarkan uraian tugasnya di institusi pendidikan kesehatan Karya Husada Kediri.

Korelasi antara stresorkerja dengan kinerja menunjukkan bahwa stresor kerja yang dialami tenaga kependidikan berhubungan dengan stresor yang berasal dari lingkungan pekerjaan.Stresor tersebut bersifat fungsional/bersifat membantu.Stresor yang dimaksud merupakan pemicu stres yang secara sederhana hal ini berarti bahwa stresor mempunyai potensi untuk mendorong atau menggangu pelaksanaan kerja, tergantung seberapa besar tingkat stres.Selain itu karena adanya tuntutan pekerjaan, menjadikan stresor yang dialami tenaga kependidikan merupakan suatu tantangan dalam menghadapi, dan menyelesaikan suatu pekerjaan yang diberikan sesuai dengan bidang pekerjaannya.
Menurut Fred Luthans menyampaikan hal yang sama bahwa secara khusus, jika karyawan merasa bahwa mereka mempunyai sedikit kontrol pada lingkungan pekerjaan dan pekerjaan mereka sendiri, maka mereka akan mengalami stres. Studi menunjukkan bahwa jika karyawan diberi kontrol pada lingkungan kerja, seperti diberi kesempatan untuk terlibat dalam proses pengambilan keputusan yang mempengaruhi mereka, hal ini akan mengurangi stres kerja. ${ }^{12}$

Korelasi Motivasi Kerja dengan Kinerja Tenaga Kependidikan Berdasarkan Uraian Tugasnya di Institusi Pendidikan Kesehatan Karya Husada Kediri

Dari hasil uji statistik tampak bahwa terdapat korelasi yang bermakna $(\mathrm{p}<0,05)$ antara motivasi kerja dengan kinerja tenaga kependidikan berdasarkan uraian tugasnya di institusi pendidikan kesehatan Karya Husada Kediri.

Hubungan seseorang dengan pekerjaannya sangat mendasar dan karena itu sikap seseorang terhadap pekerjaannya itu sangat mungkin menentukan keberhasilan dan kegagalannya. Sikap terhadap kepuasan kerja merupakan faktor yang diyakini dapat mendorong dan mempengaruhi semangat kerja karyawan agar karyawan dapat bekerja dengan baik dan secara langsung akan mempengaruhi prestasi karyawan. ${ }^{12,17}$ Motivasi terbentuk dari sikap (attitute) karyawan dalam menghadapi situasi kerja di tempat kerja.

Menurut Herzberg, kepuasan kerja menjadi menarik untuk diamati karena memberikan manfaat, baik dari segi individu maupun dari segi kepentingan organisasi. Salah satu cara yang ditempuh untuk meningkatkan kinerja yaitu keseimbangan antara sumber instrinsik maupun ekstrinsik.Motivasi sebagai dorongan karyawan untuk melakukan tindakan karena mereka ingin melakukannya. Apabila individu termotivasi, mereka akan membuat pilihan yang positif untuk melakukan 
sesuatu. Motivasi dapat muncul dari dalam diri individu masing-masing dan dapat juga dari lingkungan sekitar yaitu dari luar institusi.

Pengaruh Stresor Kerja dan Motivasi Kerja dengan Kinerja Tenaga Kependidikan Berdasarkan Uraian Tugasnya di Institusi Pendidikan Kesehatan Karya Husada Kediri

Pada pengujian hipotesis diketahui terdapat pengaruh langsung antara stresor kerja dan motivasi kerja terhadap kinerja tenaga kependidikan.Stres sebenarnya dapat sangat membantu atau bersifat fungsional, tetapi juga dapat berperan salah atau merusak kinerja.Pada penelitian ini didapatkan bahwa stresor kerja yang dialami tenaga kependidikan Karya Husada Kediri secara sederhana menyebabkan stres optimal yang mempunyai potensi untuk mendorong pelaksanaan kerja tenaga kependidikan.

Gambar 2 menyajikan model yang menunjukkan hubungan antara stres dan kinerja.Bila tidak ada stres, tantangan-tantangan kerja juga tidak ada, dan kinerja cenderung rendah.Sejalan dengan meningkatkan stres prestasi kita cenderung naik.Stres membantu karyawan untuk menggerahkan segala sumber daya dalam memenuhi berbagai persyaratan atau kebutuhan pekerjaan. Stres adalah suatu rangsangan sehat untuk memotivasi para karyawan agar memberikan tanggapan terhadap tantangan-tantangan pekerjaan. ${ }^{9}$

Tenaga kependidikan harus mempunyai motivasi dan kemampuan dalam menghadapi dan melaksanakan keseluruhan tugas-tugas yang menjadi tanggungjawabnya.Tugas-tugas tersebut biasanya berdasarkan indikator-indikator keberhasilan yang sudah ditetapkan. Sebagai hasilnya akan diketahui bahwa tenaga kependidikan masuk dalam tingkatan kinerja tertentu. Kinerja tenaga kependidikan merupakan hasil kerja karyawan baik dari segi kualitas maupun kuantitas berdasarkan standar kerja yang telah ditentukan. ${ }^{34}$ Standar kerja yang berlaku di institusi pendidikan kesehatan Karya Husada Kediri berdasarkan pada uraian tugasnya yang meliputi tiga komponen penting yaitu uraian dalam merencanakan, melaksanakan dan melaporkan/ mengevaluasi tugas masing-masing bidang pekerjaan tenaga kependidikan. ${ }^{5}$ Kinerja tenaga kependidikan akan tercapai apabila didukung oleh atribut individu, upaya kerja dan dukungan orga nisasi. ${ }^{8}$

\section{KESIMPULAN}

1. Semakin rendah stresor kerja maka semakin tinggi kinerja tenaga kependidikan berdasarkan uraian tugasnya.

2. Semakin tinggi motivasi kerja maka semakin tinggi kinerja tenaga kependidikan berdasarkan uraian tugasnya.

3. Stresor kerja dan motivasi kerja secara bersamasama berpengaruh terhadap kinerja tenaga kependidikan berdasarkan uraian tugasnya.

\section{SARAN}

Guna pelaksanaan manajemen pendidikan khususnya manajemen sumber daya manusia dengan baik dan memberikan kontribusi yang baik terhadap lulusan, tenaga kesehatan STIKES Karya Husada Kediri melalui peningkatan kinerja dan kualitas tenaga kependidikan diharapkan mulai dari pimpinan STIKES Karya Husada Kediri maupun ketua-ketua prodi berupaya mengatur sumber daya manusia agar proporsi sumber daya manusia dengan motivasi kerja yang tinggi bertambah serta mengadakan evaluasi terhadap faktor-faktor penyebab stresor tinggi dan pemecahannya.Pentingnya mengikuti pelatihan manajemen sumber daya manusia atau manajemen stres sehingga terhindar dari tahapan stresor yang tinggi dan dapat memotivasi diri agar kinerja tenaga kependidikan berdasarkan uraian tugasnya dapat tercapai secara maksimal.

\section{UCAPAN TERIMA KASIH}

Ucapan terimakasih penulis sampaikan kepada Prof. Dr. Firman F. Wirakusumah, dr., SpOG(K) selaku pembimbing utama dan Dr. R. Tina Dewi Judistiani, dr., SpOG selaku pembimbing pendamping yang telah memberikan bimbingan dengan penuh kesabaran serta arahan sejak awal penulisan hingga terselesaikannya artikel ilmiah ini. Ucapan terimakasih juga penulis haturkan kepada Dr Anita Deborah Anwar, dr. SpOG (K), selaku Ketua Program Studi Magister Kebidanan Universitas Padjajaran yang senantiasa membantu, memfasilitasi, dan memberikan bimbingan selama penulisan artikel ilmiah ini. 


\section{DAFTAR PUSTAKA}

1. Pannen P. Pendidikan sebagai sistem. Jakarta: Pusat Antar Universitas Untuk Peningkatan dan Pengembangan Aktivitas Instruksional Direktorat Jenderal Pendidikan Tinggi Departemen Pendidikan Nasional (PAU-PPAI) Universitas Terbuka. 2001; 8; 2-1.

2. Dosen. Pedoman penjaminan mutu akademik Universitas Indonesia. Badan Penjaminan Mutu Akademik Universitas Indonesia (BPMA UI). 2007; 3. Diunduh di:www.ui.ac.id/download/files/bpma/ Dosen..pdf

3. Manajemen SDM pendidikan. Diunduh di:http:// uharsputra.wordpress.com/pendidikan/manajemensdm-pendidikan/6-11-2011

4. UU RI No. 20 tahun 2003: Sistem pendidikan nasional. Diunduh di:www.inherent-dikti.net/files/ sisdiknas.pdf

5. Sekolah Tinggi Ilmu Kesehatan Karya Husada Pare Kediri. Status Tahun Akademik 2008/2009.

6. Sutisna M. Konsep pendidikan tinggi dan filosofi penyelenggaraan program diploma, Bandung: Pusbandik Politeknik dan Progam Diploma; 2006.

7. Rivai V. Manajemen sumber daya manusia untuk perusahaan: Dari teori Kepraktik. Edisi ke-3. Jakarta: Rajawali Pers. 2010: 584-547, 839-837, 1012-1008.

8. Mangkunegara AAAP. Evaluasi kinerja SDM. Bandung: Rifka Aditama. Juli 2010; 5: 29-9, 77-61.

9. Handoko TH. Manajemen personalia dan SDM. Yogyakarta: BPFE. Agustus 2001; 5: 204-199.

10. Schuler, E. Definition and conceptualization of stres in organizations, Thousand Oaks: Sage. 2002: 189.

11. Rini JF. Stres kerja. Jakarta: 1 Maret 2002. Diunduh di: www.teame-psikologi.com

12. Luthans F. Perilaku organisasi. Yogyakarta: Andi. 2006; 10: 286-288.

13. Ahsan N, Abdullah Z, Yong GFD, Shah AS. A Study of job stres on job satisfication among University staff in Malaysia. European journal of sosial sciences. 2009; 8: 1 .

14. National Safety Council. Manajemen Stres. Jakarta: EGC. 2004.

15. Kandasamy K. Bab 2 Tinjauan pustaka konsep stres. Repository.usu.ac.id. 2011.

16. Van DHP, et al. High workload and job stres are associated with lower practice performance in general practice: an observational study in 239 General Practice in the Netherlands. BMC health services research. 15 July 2009.

17. Siagian SP. Teori motivasi dan aplikasinya. Jakarta: Rineka Cipta. Juli 2004; 3: 140-125.
18. Staren ED. Optimizing staff motivation. In leadership article. Juli-Agustus 2009.

19. Robbins SP, Judge TA. Perilaku organisasi. Jakarta: Salemba Empat. 2008; 1(12): 253-220, 324-311.

20. Moeheriono. Pengukuran Kinerja Berbasis Kompetensi. Jakarta: Ghalia Indonesia. Oktober 2009. hlm. 60-144.

21. Fahmi I. Manajemen Kinerja Teori Dan Aplikasi. Bandung: Alfabeta. Desember 2010.hlm. 75-64.

22. Samsudi S. Manajemen Sumber Daya Manusia. Edisi ke-1. Bandung: CV. Pustaka Setia. Maret 2006. hlm. 159.

23. Garniwa I, Penelitian mandiri. Pengaruh stres kerja terhadap motivasi serta dampaknya terhadap prestasi kerja dosen tetap Universitas Widyatama. 2007. Diunduh di:www.google.com.jurnal.pdii.lipi.go.id/ admin/jurnal/6209115126_1829-8540.pdf

24. Fakultas Ilmu Pendidikan Universitas Pendidikan Indonesia. Pedoman Penilaian Kinerja UPI. 2009. Diunduh di: www.file.upi.edu/Direktori/FIP/ Jur.PEDAGOGIK/pedoman_kinerja.pdf

25. Dessler G. Manajemen sumber daya manusia. Klaten: PT. Intan Sejati. 2006;1(10): 350-321.

26. Jackson JH, Mathis RL. Manajemen Sumber Daya Manusia. Jakarta: PT. Salemba Emban Patria. 2002; 108-75.

27. Sartono M. Peningkatan Kinerja Profesi Tenaga Kependidikan Melalui Kegiatan Pelatihan Berbasis ICT Dan WEB. Diunduh di: http:// www.slideshare.net/sarhaji/peningkatan-kinerjaprofesi-tenaga-pendidikan

28. Tampubolon DP. Perguruan Tinggi Bermutu. Jakarta: PT. Gramedia Pustaka Utama. 2001; 171-195.

29. Departemen Pendidikan Nasional Direktorat Jenderal Pendidikan Tinggi Direktorat Akademik. Pedoman kompetisi kualitas layanan akademik tenaga administrasi Akademik. Jakarta. 2009.

30. Istijanto OEI. Riset sumber daya manusia. Jakarta: PT. Gramedia Pustaka Utama. 2010; 4: 186-190, 237.

31. Kousar S. Doger IA. Ghozal S. Khattak I. Occupatoinal Stres and Job Performance Original Article. Journal Pakistan of Psichiatric Society. JulyDecember 2006; 3(2).

32. Manajemen pendidikan di indonesia tahun 2011. Diunduh di: www.http//edukasi.kompasian.com.

33. Manajemen Pendidikan di Indonesia tahun 2010. Diunduh di: www.http//edukasi.kompasian.com.

34. Kementrian Pendidikan Nasional Direktorat Jenderal Pendidikan Tinggi Direktorat Pendidik dan Tenaga Kependidikan. Pedoman Umum Pemilihan Tenaga Administrasi Akademik Berprestasi tahun 2011. 
35. Bab 2 Tinjauan Pustaka Stres Kerja. Diunduh di:www.damandri.or.id/file/novitasari

36. Milbourn G. Teaching the job stres Audit to Business School Student: Causes, measures, reduction, Journal of American Academy of Business. 2006; 8(2): 44-50.

37. Holmstrom S, Molander B, Jansson J, Bergqvist MB. Evaluation of a Swedish version of the Job Stres Survey. Scandinavian Journal of Psychology. 2008; 49: 277-286.

38. Radityo R. Hubungan sumber stres kerja dengan kinerja karyawan perusahaan teknologi informasi pada PT.X. FPSi UI. 2009.

39. Mayor JD, Faber MA, Xu X. SeventFive years of motivation measures (1930-2005): A Descriptive analysis. 2007 March.

40. Russel CJ, Bobko P. Moderated regression analysis And likert scale too coarse for comfort. Journal of applied psychology. June 1992; 77(3): 336-342.

41. Direktorat Jenderal Pendidikan Tinggi Departemen Pendidikan Nasional. Buku II Penyusunan Portofolio. Jakarta. 2009.
42. Badan Akreditasi Nasional Perguruan Tinggi. Akreditasi Program Studi Diploma. Jakarta. 2009.

43. Satari MH, Wirakusumah FF. Konsistensi Penelitian Dalam Bidang Kesehatan. Bandung: PT. Refika Aditama. 2011.

44. Yosep I. Keperawatan Jiwa. Bandung: PT. Resika Aditama. 2007

45. Devonport TJ, Biscom K, Lane AM. Sources of Stres and the Use of Anticipatory, Preventative and Proactive Coping Strategies by Higher Education Lecturers. JOHLSTE. 7(1): 1473-8376

46. Darman. Manajemen Konflik dan Stres Kerja. UMB: Pusat Pengembangan Bahan Ajar. 2007. hlm.7-15.

47. Hubungan Motivasi terhadap Kinerja Pegawai Sekolah Tinggi Ilmu Agama Tulungagung. www.ilmiahpendidikan.com. Diunduh tgl 1242012. 